\title{
An evaluation of urinary microRNA reveals a high sensitivity for bladder cancer
}

\author{
S Miah 1,2, E Dudziec ${ }^{1,2}$, RM Drayton ${ }^{1,2}$, AR Zlotta ${ }^{3}$, SL Morgan $^{4}$, DJ Rosario', FC Hamdy ${ }^{5}$ and JWF Catto*, 1,2 \\ 'Academic Urology Unit, University of Sheffield Medical School, Beech Hill Road, Sheffield SIO 2RX, UK; ${ }^{2}$ Institute for Cancer Studies, University of \\ Sheffield Medical School, Beech Hill Road, Sheffield SIO 2RX, UK; ${ }^{3}$ Department of Surgery (Urology), Mount Sinai Hospital, 600 University Avenue, \\ Toronto Ontario M5G IX5, Canada; ${ }^{4}$ Department of Pathology, Royal Hallamshire Hospital, Glossop Road, Sheffield SI 0 2JF, UK; ${ }^{5}$ Nuffield Department \\ of Surgery, University of Oxford, John Radcliffe Hospital, Oxford OX3 9DU, UK
}

BACKGROUND: Urinary biomarkers are needed to improve the care and reduce the cost of managing bladder cancer. Current biomarkers struggle to identify both high and low-grade cancers due to differing molecular pathways. Changes in microRNA (miR) expression are seen in urothelial carcinogenesis in a phenotype-specific manner. We hypothesised that urinary miRs reflecting low- and high-grade pathways could detect bladder cancers and overcome differences in genetic events seen within the disease. METHODS: We investigated urinary samples $(n=121)$ from patients with bladder cancer $(n=68)$ and age-matched controls $(n=53)$. Fifteen miRs were quantified using real-time PCR.

RESULTS: We found that miR is stable within urinary cells despite adverse handling and detected differential expression of 10 miRs from patients with cancer and controls (miRs - I5a/I5b/24-I/27b//00//35b/203/212/328/I224, ANOVA P<0.05). Individually, miR-1224-3p had the best individual performance with specificity, positive and negative predictive values and concordance of $83 \%$, $83 \%, 75 \%$ and $77 \%$, respectively. The combination of miRs-135b/I5b//224-3p detected bladder cancer with a high sensitivity (94.1\%), sufficient specificity (51\%) and was correct in $86 \%$ of patients (concordance).

CONCLUSION: The use of this panel in patients with haematuria would have found $94 \%$ of urothelial cell carcinoma, while reducing cystoscopy rates by $26 \%$. However, two invasive cancers (3\%) would have been missed.

British Journal of Cancer (2012) 107, 123-128. doi:10.1038/bjc.2012.221 www.bjcancer.com

Published online 29 May 2012

(c) 2012 Cancer Research UK

Keywords: microRNA; urine; bladder cancer

Bladder cancer is the fifth commonest malignancy in the United States with 70530 new cases and 14680 deaths in 2010 (Jemal et al, 2010). The majority of urothelial cell carcinoma (UCC) is low grade and non-muscle invasive. These are managed by endoscopic resection with intra-vesical chemotherapy, and have an excellent prognosis. Approximately $1 / 3$ of UCC is high-grade and arises from carcinoma in-situ. High-grade UCC is an aggressive disease that may be detected before or with muscle invasion. Despite radical therapy the mortality from invasive UCC is a round $50 \%$, reflecting the late stage at diagnosis and a poor response to chemotherapy (Schrier et al, 2004). The relapsing natural history of UCC and the frequency of suggestive symptoms mean that many patients undergo diagnostic or repeated surveillance endoscopic inspection of their bladder. Consequently, bladder cancer is one of the most-expensive human malignancies. Estimates suggest the disease costs around $\$ 3.7$ billion/per annum in the US and the majority of this cost is spent on diagnosis and surveillance of disease (Sangar et al, 2005; Avritscher et al, 2006).

A robust urinary biomarker to detect UCC would considerably improve the care of patients with and reduce the cost of managing bladder cancer. Urine cytology is the most used non-invasive urinary test for UCC. It has a high specificity but a low sensitivity for UCC and is poor at detecting low-grade tumours (Planz et al, 2005;

*Correspondence: Dr JWF Catto; Email: J.Catto@sheffield.ac.uk Revised 13 April 2012; accepted 25 April 2012; published online 29 May 2012
Carmack and Soloway 2006). Multiple molecular urinary biomarkers have been investigated to date, but none are sufficiently robust to enter clinical practice (Zwarthoff 2008). Many biomarkers fail as they are unable to detect both low and high-grade UCC, which are characterised by distinct molecular pathways and share few molecular alterations (Catto et al, 2005, 2009, 2010). Biomarker panels that assess molecular events characteristic of low- and high-grade UCC improve the accuracy of urinary tests, but are laborious (van Rhijn et al, 2003).

MicroRNAs (miRs) are short non-coding RNA molecules that post-transcriptionally modulate protein expression (Catto et al, 2011). Alterations in $\mathrm{miR}$ expression appear important for carcinogenesis (He et al, 2005; Voorhoeve et al, 2006) and those with differential expression between normal urothelium and UCC have recently been described (Catto et al, 2009; Dyrskjot et al, 2009). Their expression varies with disease phenotype and reflects genetic or epigenetic events within the low- and high-grade UCC pathways (Dudziec et al, 2011). Here, we test the hypothesis that urinary miR expression can detect bladder cancer. Urine contains many nucleases, and assays to examine mRNA expression often fail due to target degradation or require stringent prelaboratory handling of the urine sample. Short RNA molecules are less prone to degradation than long polyadenylated mRNAs and may be stabilized by secretion within exosomes (Valadi et al, 2007). Recently, urinary miR expression has been reported and the upregulation of miRs-126/182/199a found to discriminate patients with UCC from disease-free controls (Hanke et al, 2009). 
This combination identified up to $77 \%$ of UCC cases, despite a lack of differential expression for any of these miRs in malignant and normal urothelium (Catto et al, 2009). We hypothesise that analysing the expression of miRs characteristic of high- and lowgrade UCC could improve the performance of a miR-based urinary test for the disease.

\section{MATERIALS AND METHODS}

\section{Patients and samples}

We studied freshly voided urine samples obtained from 121 patients of the Department of Urology, Royal Hallamshire Hospital, UK (Table 1). These included 68 patients with current UCC (both new and recurrent tumours) and 53 age-matched controls without a history of UCC. Controls included those requiring cystoscopy for symptoms suggestive of UCC (e.g. haematuria), those undergoing treatment of benign urinary conditions and patients without urinary pathology. Most patients with urinary symptoms, uropathology or haematuria underwent cystoscopy $(50 / 53,94 \%)$. Around $100-150 \mathrm{ml}$ of urine was collected from each patient before instrumentation or bladder tumour removal. Tumours were classified using the 1973 WHO criteria by a specialist uropathologist (SLM). Informed consent was obtained from each patient and institutional ethics committee approval gained before commencing the study.

\section{Urine processing and RNA extraction}

Freshly voided urine was stored at $4{ }^{\circ} \mathrm{C}$ for up to $4 \mathrm{~h}$ and then centrifuged at $3392 \mathrm{~g}$ for $10 \mathrm{~min}$. The supernatant was removed and the cell pellet washed twice in PBS before freezing at $-80^{\circ} \mathrm{C}$ until

Table I Patients and tumours studied in this report

\begin{tabular}{|c|c|c|c|c|}
\hline & \multicolumn{2}{|c|}{ Controls } & \multicolumn{2}{|c|}{ UCC cases } \\
\hline & $n$ & $\%$ & $n$ & $\%$ \\
\hline \multicolumn{5}{|l|}{ Gender } \\
\hline Male & 35 & 66 & 53 & 78 \\
\hline Female & 18 & 34 & 15 & 22 \\
\hline \multicolumn{5}{|l|}{ Age } \\
\hline Median & 62 & & 72 & \\
\hline Average & 58 & & 71 & \\
\hline Range & $17-83$ & & $38-87$ & \\
\hline Haematuria & 28 & 53 & & \\
\hline Urolithiasis & 10 & 19 & & \\
\hline Urinary infection & 6 & 11 & & \\
\hline BPH (TURP) & 6 & 11 & & \\
\hline Other & 3 & 6 & & \\
\hline \multicolumn{5}{|l|}{ Differentiation } \\
\hline Grade I & & & 15 & 22 \\
\hline Grade 2 & & & 21 & 31 \\
\hline Grade 3 & & & 32 & 47 \\
\hline \multicolumn{5}{|l|}{ Stage } \\
\hline pTa & & & 33 & 49 \\
\hline pTis & & & 4 & 6 \\
\hline pTI & & & 4 & 6 \\
\hline рT2-4 & & & 27 & 40 \\
\hline Total & 53 & & 68 & \\
\hline
\end{tabular}

Abbreviations: $\mathrm{BPH}=$ benign prostatic hyperplasia; TURP = trans-urethral resection of prostate; UCC = urothelial cell carcinoma. Various controls including circumcision (I), pulmonary embolus (I), appendicitis (I). use. To determine miR stability in urine, we split 25 samples into three fractions (50 $\mathrm{ml}$ for each) and separately extracted RNA in the form of two reference genes (RNU48 and RNU44) and three miRs (15b/135b/1224-3p) from an immediately processed sample, following three cycles of freeze-thawing $\left(-80^{\circ} \mathrm{C}\right.$ to room temperature) and following storage at room temperature for $48 \mathrm{~h}$. We also compared miR yield using matched samples collected into an empty container and into one containing $50 \%$ volume RNase inhibitor. RNA was extracted from cell pellets using the mirVana kit (Ambion, Austin, TX, USA) according to the manufacturer's protocol and measured using a 2100 Bioanalyzer (Agilent, Stockport, UK).

\section{MiR detection}

The expression of 15 miRs was measured using real-time PCR. We selected miRs including (i) those with differential expression in malignant and normal urothelium, (ii) miRs with up- and downregulation in UCC, (iii) miRs representative of all UCC
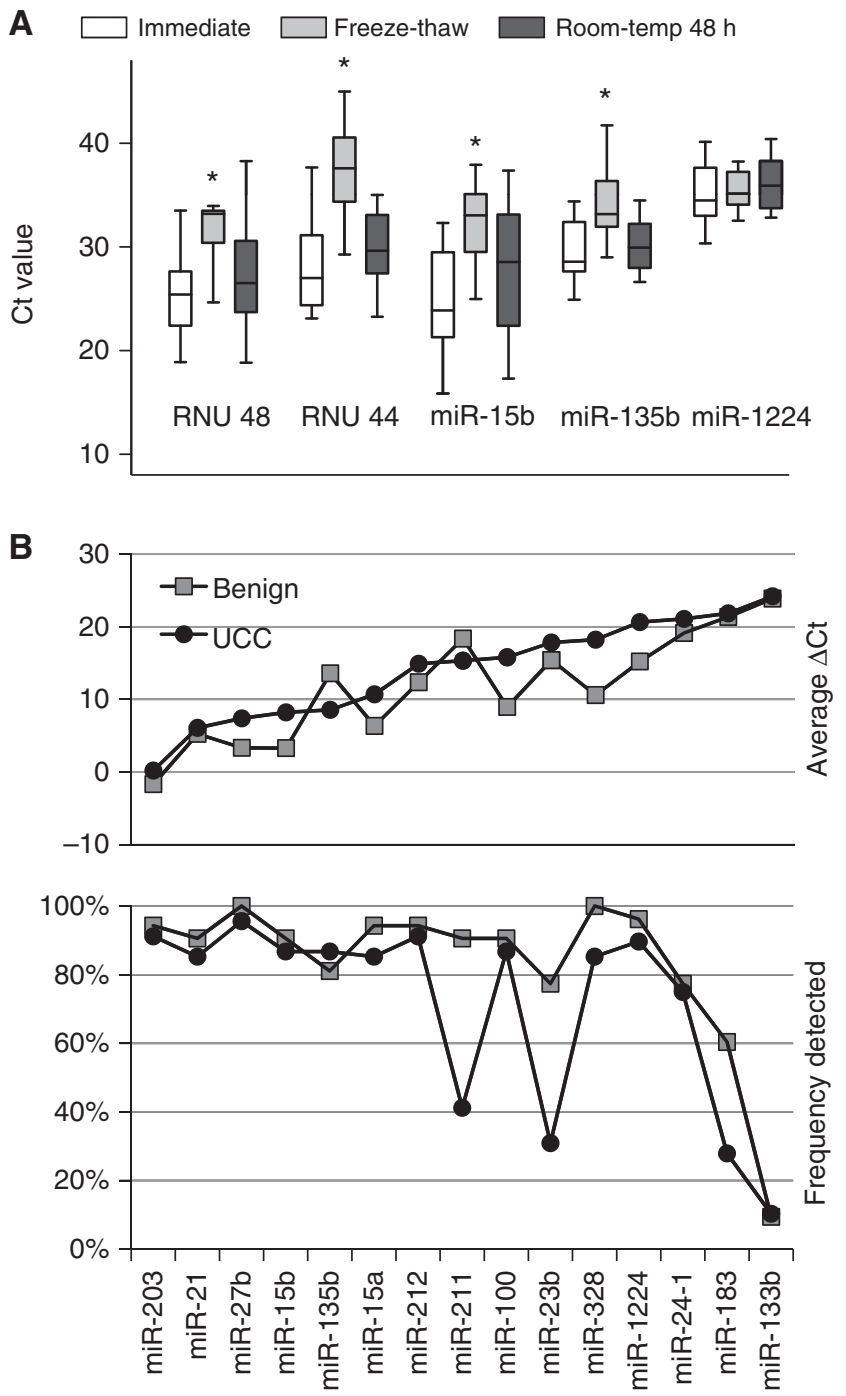

Figure I Detection of microRNA in urinary cell pellets. (A) The expression (presented as Ct value) of RNU48 and RNU44 and selected miRs in urine samples undergoing various processing protocols. $* P$-value $<0.001$. (B) The relative expression (presented as the average $\Delta$ Ct value) and the frequency of detection for each miR analysed is shown. MiRs with higher expression are detected more frequently and therefore make better biomarkers. 
(miR-135b), of high-grade UCC (miR-21) and of low-grade UCC (miRs-100/133b), (iv) miRs subject to epigenetic regulation (miRs212/328/1224-3p) and (v) those located in an epigenetic hotspot on chromosome 9 (miRs-23b/24-1/27b: a chromosome commonly deleted in UCC) (Dudziec et al, 2011). We included RNAs with low and high cellular expression to estimate the necessary abundance for analytical reliability. Quantitation was determined relative to snoRNA's, of which we evaluated RNU44 and RNU48. Complementary DNA synthesis was performed using 1-350 ng RNA, multiplex hairpin primers (Megaplex RT Primers, Applied Biosystems, Warrington, UK), $100 \mathrm{~mm}$ deoxynucleotide triphos-

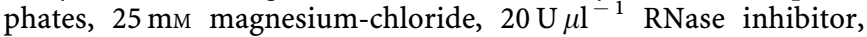
nuclease-free water, buffer and Multiscribe Reverse Transcriptase (Applied Biosystems). This reaction was subjected to 40 cycles of $16^{\circ} \mathrm{C}$ for $2 \mathrm{~min}, 42^{\circ} \mathrm{C}$ for $1 \mathrm{~min}$ and $50^{\circ} \mathrm{C}$ for $1 \mathrm{~min}$, before heating to $85^{\circ} \mathrm{C}$ for $5 \mathrm{~min}$. We used a nested PCR approach to determine cDNA concentration, as our starting RNA concentration was low. Reverse transcribed cDNA $(2.5 \mu \mathrm{l})$ was added to a commercially mixed buffer, polymerase and dNTPs (Pre-Amp Mastermix, Applied Biosystems), and mixed with nested primers (Megaplex Pre-Amp primers, Applied Biosystems) and nuclease-free water. This reaction was heated to $95^{\circ} \mathrm{C}$ for $10 \mathrm{~min}, 55^{\circ} \mathrm{C}$ for $2 \mathrm{~min}$, $72{ }^{\circ} \mathrm{C}$ for $2 \mathrm{~min}$ followed by 12 cycles of $95^{\circ} \mathrm{C}$ for $15 \mathrm{~s}, 60^{\circ} \mathrm{C}$ for $15 \mathrm{~s}$ after which it was finally heated to $99.9^{\circ} \mathrm{C}$ for $10 \mathrm{~min}$. Real-time PCR was conducted using this nested cDNA product, nuclease-free water, Mastermix (TaqMan Pre-Amp Mastermix, Applied Biosystems) and individual miR primers and probes. This reaction was analysed using an ABI 7900HT real-time PCR system. Amplification plots were checked manually using detection software (SDS Version. 2.2.1, Applied Biosystems) to confirm the $\mathrm{Ct}$ value corresponded with the midpoint of logarithmic amplification.

\section{Statistical methods}

Relative miR concentrations were calculated with respect to reference snoRNAs $(\Delta \mathrm{Ct}=\mathrm{Ct} \mathrm{miR}-\mathrm{Ct}$ reference $)$ and inter-class fold changes computed using the $2^{-\Delta \Delta \mathrm{Ct}}$ function (Schmittgen et al, 2008). Comparisons were performed using Chi squared and $T$-tests or ANOVA tests, as appropriate. Concordance with diagnosis was calculated as described by Harrell (Catto et al, 2009). Unsupervised hierarchical clustering was performed using $\Delta \mathrm{Ct}$ values in Cluster 3.0 and visualised in Tree view (Eisen Lab, www.rana.lbl.gov).

\section{RESULTS}

\section{Urinary miR collection, extraction and quantification}

Before the sample collection we evaluated three aspects of miR handling and quantification. Firstly, we investigated the use of an RNase inhibitor. We found urinary miR yields were no different with or without the use of RNase inhibition (data not shown) and so collected samples into empty universal containers. Secondly, we subjected matching fractions from 25 freshly-frozen and thawed urine samples to (i) immediate processing, (ii) storage at room temperature for $48 \mathrm{~h}$ and (iii) three cycles of freeze-thawing. No statistical difference in yield was shown for both the reference genes RNU48 and RNU44, and miRs-15b/-135b/-1224-3p between urine samples that were immediately processed and those that were stored in room temperature for $48 \mathrm{~h}$ before extraction (Figure 1A). However, freeze-thawing did reduce yields for several RNAs when compared with immediate processing. We used immediate processing for the samples in this report. Thirdly, we compared two snoRNAs to identify the best reference molecule for relative miR quantification. RNU48 was detected in all cases, with a higher and less variable expression

Table 2 MicroRNA expression in urinary samples from patients with bladder cancer and controls

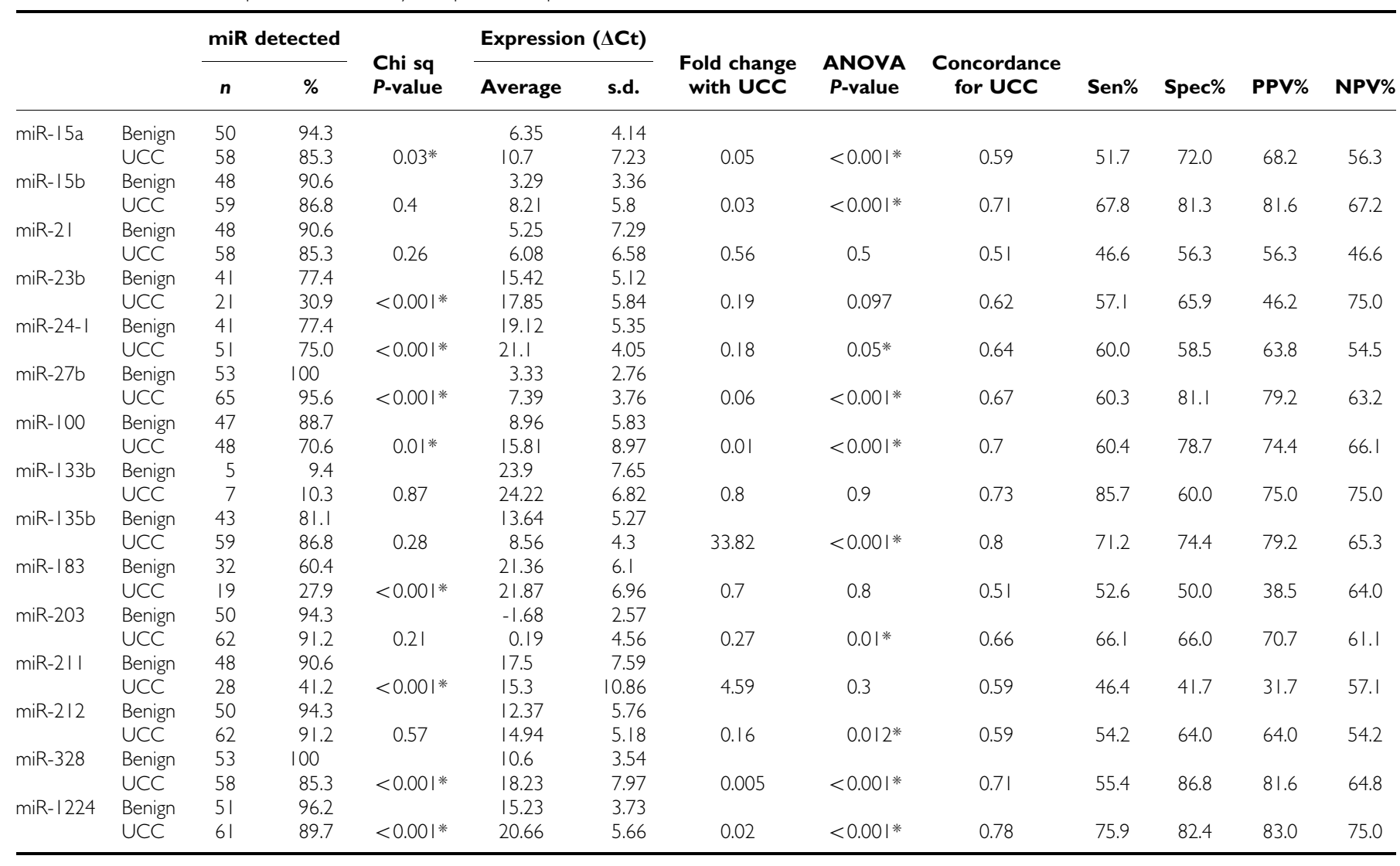




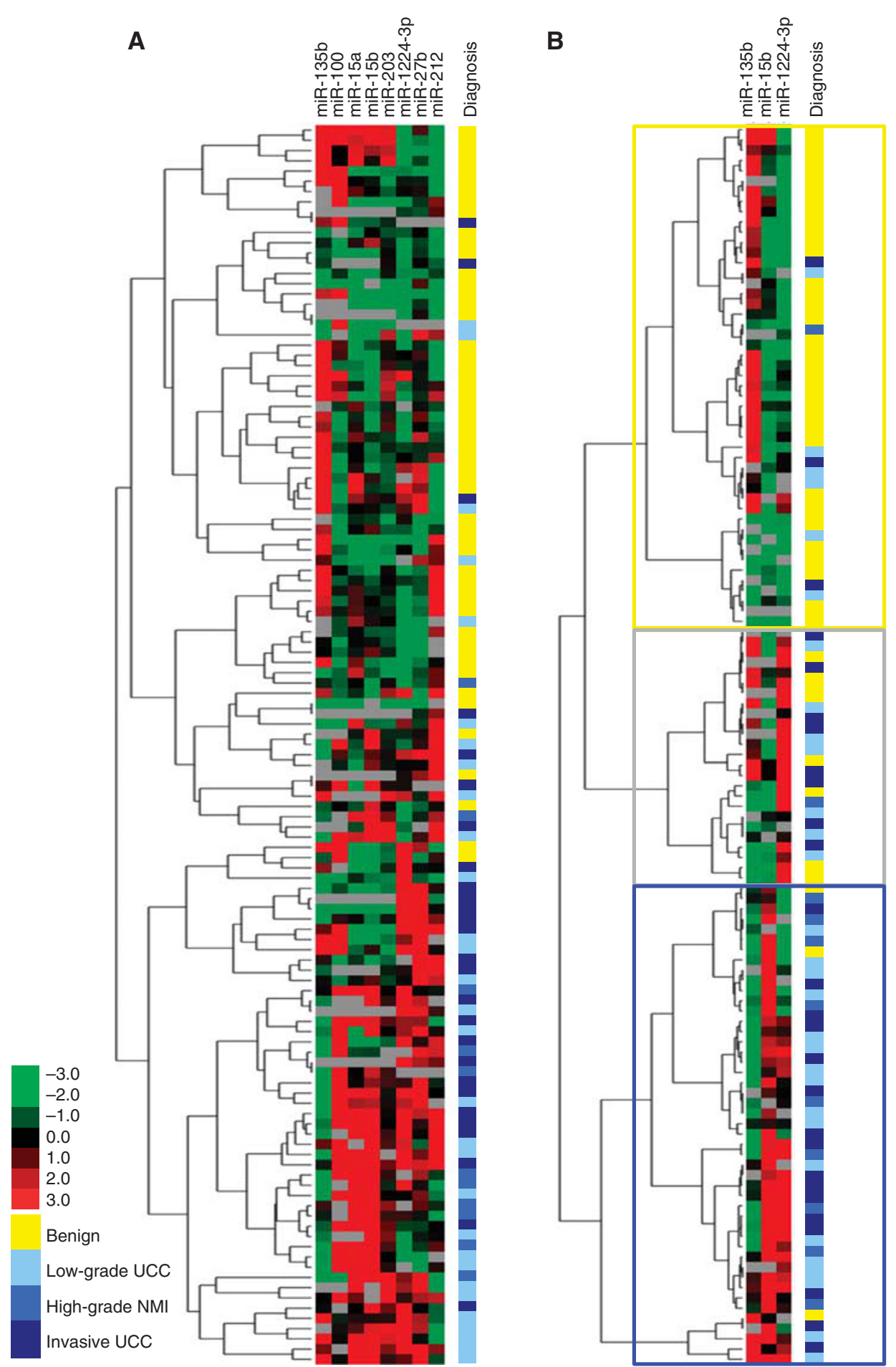

Figure 2 Expression of microRNA in urinary cell pellets. Unsupervised hierarchical clustering using either $(\mathbf{A})$ eight or $(\mathbf{B})$ three selected miRs identifies tree branches that mostly correspond to the underlying diagnosis. Average linkage correlation (uncentered) was performed on mean centred $\Delta \mathrm{Ct}$ values using Cluster 3.0. Samples are colour-labelled according to the pathology.

$(n=121(100 \%)$, Ct average \pm s.d.: $20.8 \pm 4.3)$ than RNU44 $(n=114$ (94\%), Ct $28.7 \pm 6.45)$. We chose RNU48 as the reference RNA.

\section{Urinary miR expression in patients with bladder cancer and controls}

Expression of $\mathrm{miR}$ varied by 30 -million-fold from the lowest (miR-133b) to highest (miR-203) $(\Delta \Delta \mathrm{Ct}=-24.8$, Figure $1 \mathrm{~B})$. MicroRNAs with low concentration were less frequently detected than those with high expression ( $10 \%$ vs $93 \%$, respectively, Chi sq $P<0.001$ ). Reliable detection (e.g. in $>80 \%$ of samples) was seen in miRs with a 9000 fold change in expression (miR-203 to miR$100, \Delta \Delta \mathrm{Ct}=-13.1$, fold change $=8964)$. The miRs were detected more frequently in urinary samples from benign than UCC cases (Table 2). This difference reached significance for nine miRs (miRs-15a/15b/24-1/27-b/100/203/212/328/1224 (Chi Sq $P<0.03$ )). Quantification revealed differences in expression for $10 \mathrm{miRs}$ between benign and malignant cases (ANOVA $P<0.05$ ). Patients 
A
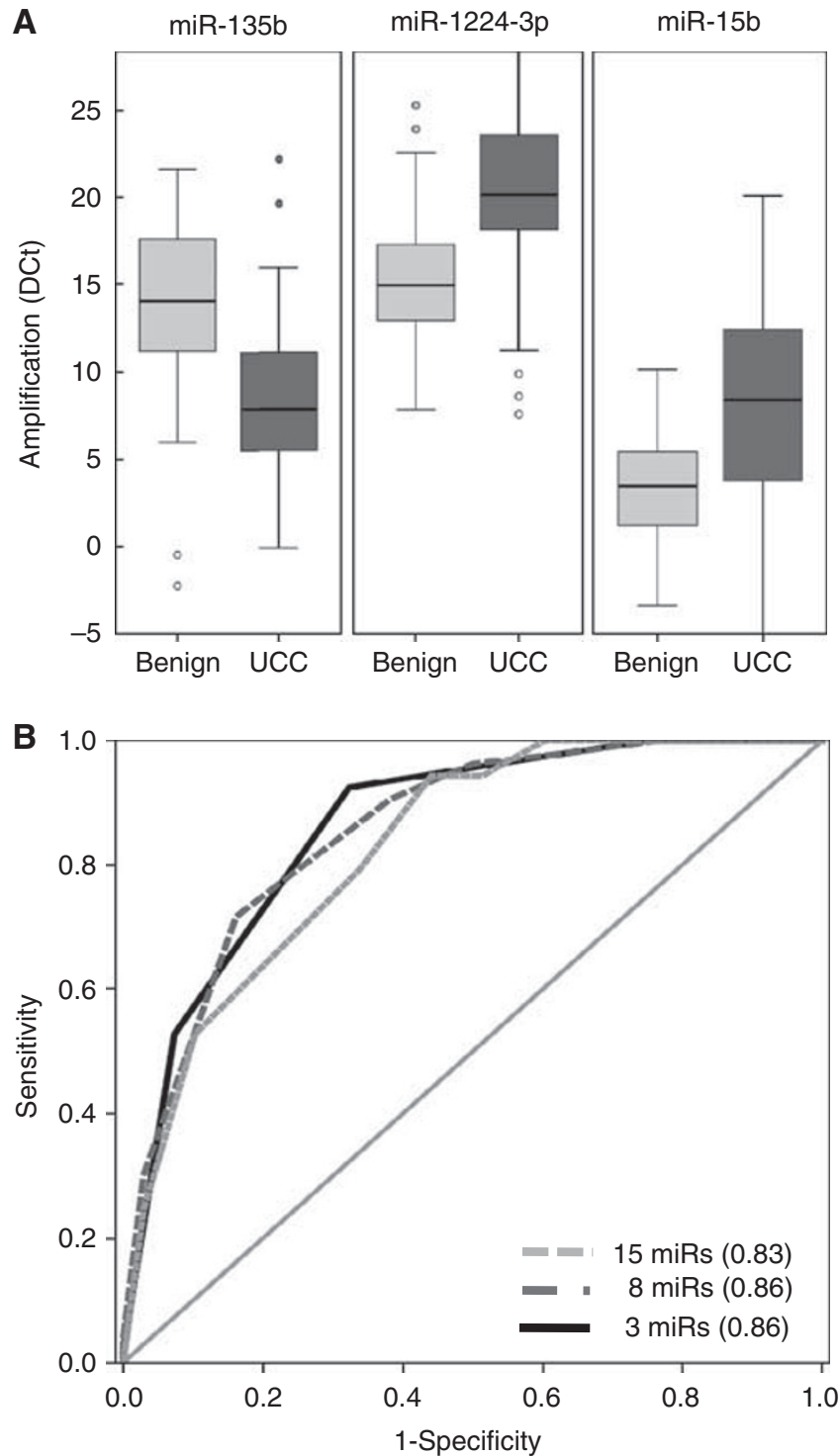

Figure 3 MicroRNAs-135b/I5b//224-3p and the diagnosis of bladder cancer. (A) Box plots show the expression profiles of each microRNA according to the presence of bladder cancer (box $=95 \% \mathrm{Cl}$ and median $=$ dark central bar). (B) Receiver operator curve for these two microRNAs alone and in combination for the detection of UCC (area under curve in brackets).

with UCC had lower expression of miRs-15a/15b/24-1/27b/100/ 203/212/328/1224-3p and higher expression of miR-135b, when compared with controls.

\section{Non-invasive diagnosis of bladder cancer}

We calculated the diagnostic performance for UCC of the differentially expressed miRs, using expression dichotomized around the mean $\Delta \mathrm{Ct}$ (Figure 2). The accuracy of individual miRs varied from 0.61 to 0.80 for UCC (Concordance indices, Table 2). The sensitivity and specificity for UCC ranged from $51.7 \%$ (miR$15 \mathrm{a})$ to $75.9 \%$ (miR-1224-3p) and $58.5 \%$ (miR-24-1) to $86.8 \%$ (miRs-212/328), respectively. MiR-1224-3p had the best individual performance with specificity, positive and negative predictive values of $83 \%, 83 \%$ and $75 \%$, respectively. The combination of miRs improved their diagnostic performance. The best concordance for UCC was achieved using either a combination of eight (C-index 0.86, miRs-15a/15b/27b/100/135b/203/212/1224-3p) or three miRs (C-index 0.86, miRs-15b/135b/1224-3p, Figure 3). The three miR combination appeared most sensitive for UCC $(94.1 \%)$, but had a low specificity (51\%). Clustering using these selected panels separated the samples into two large cohorts representing mostly benign or UCC cases, and a small intermediate group $(n=23,19 \%$; Figure 3$)$.

\section{DISCUSSION}

Here, we have shown that urinary miRs appear promising biomarkers for the detection of bladder cancer. When compared with previously analysed candidates, their stability and flexibility in measurement makes them appealing diagnostic targets. By incorporating miRs with known changes in UCC, we found it possible to design a panel with a high sensitivity for the disease. Of note, when implementing a urinary test to stratify the need for cystoscopy, it is sensitivity (to reduce false negative tests) that is more important than specificity.

Firstly, the expression of urinary miRs appears stable ex vivo when stored at room temperature. This stability may be due to their small size that makes them less likely to fragment than large RNAs, their lack of polyadenylated tail that nucleases target (Guhaniyogi and Brewer 2001), or that they are secreted within exosomes, which protect RNA from degradation (Valadi et al, 2007). Exogenously administered free miR undergoes rapid clearance in biological fluids, suggesting the inclusion within an exosome is critical for protection (Mitchell et al, 2008). This ex vivo stability is important in clinical use, where transit to laboratory of biological samples is inconsistent.

Secondly, it is possible to multiplex miR assays into custom combinations to detect specific diseases. With this in mind, we selected 15 miRs whose expression is relatively UCC-specific and were representative of the low- and high-grade tumour pathways (Catto et al, 2009, 2011). We included those with functional roles in urothelial carcinogenesis, such as growth promotion through FGFR3 targeting (miR-100) and apoptosis avoidance/cell cycle regulation (miR-21), and those with epigenetic regulation (e.g. miR-1224-3p). We found that low abundance miRs are not reliably detected in urinary cells, even though their expression may be UCC-specific (such as miR-133b). We identified 13 miRs whose urinary presence or expression was abnormal in the UCC patients when compared with controls. Of these, several had alterations that matched primary tumours and was in keeping with their carcinogenic roles (e.g. miR-135b and miR-100). Potentially the most useful was miR-135b, as this was one of only two upregulated species and is one of the most overexpressed miRs UCC tissue (Catto et al, 2009). Similar observations are detailed in colorectal cancer, where miRs-135b/135a are implicated in APC silencing (Nagel et al, 2008). In UCC, predicted targets for miR-135b include LATS2 (Catto et al, 2009) and Annexin A7. When combined, we found three miRs with a high sensitivity for UCC (miRs-135b/15b/1224-3p (94.1\%)). Implementing this panel in our cohort, would have avoided $31(26 \%)$ cystocopies, but missed four cancers. Of these, two were invasive and two low-grade non-invasive UCC (thus, the risk of missing a significant tumour was $2 / 63(3 \%))$.

Our experiments revealed that most urinary miRs are downregulated in the presence of UCC, when compared with controls. This was a surprising outcome as we selected several that are upregulated in UCC. The RNA within urinary cells and exosomes may be derived from bladder tumours, from the normal urothelium or be filtered from the glomerulus and secreted by the renal tubules (Johnstone and Holzman 2006). As such the changes we observed may reflect events within the urothelium or the host's response to disease, masking tumour-specific miR changes. 
Recent work has reported the use of three miRs in the detection of UCC (Hanke et al, 2009). The authors screened pooled urine samples from healthy controls, controls with urinary infections, patients with low-grade UCC and from patients with high-grade UCC for the expression of 157 miRs. They found miRs-126/152/ 199a were overrepresented in the urine from UCC cases and analysed these in a further 47 samples $(n=11$ controls and $n=36$ patients with UCC). In isolation or combination the three miR panel detected up to $77 \%$ of UCC cases (sensitivity $55 \%$, specificity $82 \%)$. However, either of their selected miRs was altered in the UCC specimens we previously analysed (Catto et al, 2009). Of note, in this report miR expression was normalised against miR-152. We found miR-152 had reduced expression in UCC (fivefold lower than normal urothelium) and thus may be a poor reference target. MiR-152 is located within a CpG island on Chromosome 17 and it's silencing by hypermethylation has been observed in breast cancer (Lehmann et al, 2008).

To conclude, urinary miRs appear promising biomarkers for bladder cancer. We identified a panel of three miRs whose use would have found $94 \%$ of UCC, while reducing cystoscopy rates by
$26 \%$ in patients with haematuria. However, this panel would have missed two invasive cancers $(3 \%)$.

\section{ACKNOWLEDGEMENTS}

We wish to thank Messrs Anderson, Chapple, Hastie, Hall, Inman, Oakley and Smith for allowing us to study their patients. We thank the staff and patients of the Department of Urology, Royal Hallamshire Hospital, Sheffield, UK. This work was kindly supported by a GSK Clinical Scientist fellowship (JWF Catto), grants to JWF Catto from Yorkshire Cancer Research and the European Union (European Community's Seventh Framework Programme. Grant numbers: FP7/2007-2013, HEALTH-F2-2007201438), and a fellowship to $S$ Miah from The Urological Foundation.

\section{Conflict of interest}

The authors declare no conflict of interest.

\section{REFERENCES}

Avritscher EB, Cooksley CD, Grossman HB, Sabichi AL, Hamblin L, Dinney CP, Elting LS (2006) Clinical model of lifetime cost of treating bladder cancer and associated complications. Urology 68(3): 549-553

Carmack AJ, Soloway MS (2006) The diagnosis and staging of bladder cancer: from RBCs to TURs. Urology 67(3 Suppl 1): 3-8; discussion 8-10

Catto JW, Abbod MF, Linkens DA, Larre S, Rosario D J, Hamdy F C (2009) Neurofuzzy modeling to determine recurrence risk following radical cystectomy for nonmetastatic urothelial carcinoma of the bladder. Clin Cancer Res 15(9): 3150-3155

Catto JW, Abbod MF, Wild PJ, Linkens DA, Pilarsky C, Rehman I, Rosario DJ, Denzinger S, Burger M, Stoehr R, Knuechel R, Hartmann A, Hamdy FC (2010) The application of artificial intelligence to microarray data: identification of a novel gene signature to identify bladder cancer progression. Eur Urol 57(3): 398-406

Catto JW, Alcaraz A, Bjartell AS, De Vere White R, Evans CP, Fussel S, Hamdy FC, Kallioniemi O, Mengual L, Schlomm T, Visakorpi T (2011) MicroRNA in prostate, bladder, and kidney cancer: a systematic review. Eur Urol 59(5): 671-681

Catto JW, Azzouzi AR, Rehman I, Feeley KM, Cross SS, Amira N, Fromont G, Sibony M, Cussenot O, Meuth M, Hamdy FC (2005) Promoter hypermethylation is associated with tumor location, stage, and subsequent progression in transitional cell carcinoma. J Clin Oncol 23(13): 2903-2910

Catto JW, Miah S, Owen HC, Bryant H, Myers K, Dudziec E, Larre S, Milo M, Rehman I, Rosario DJ, Di Martino E, Knowles MA, Meuth M, Harris AL, Hamdy FC (2009) Distinct microRNA alterations characterize highand low-grade bladder cancer. Cancer Res 69(21): 8472-8481

Dudziec E, Miah S, Choudhury HMZ, Owen HC, Blizard C, Glover M, Hamdy FC, Catto JW (2011) Hypermethylation of CpG Islands and Shores around specific MicroRNAs and Mirtrons is associated with the phenotype and presence of Bladder Cancer. Clin Cancer Res 17(6): 1287-1296

Dyrskjot L, Ostenfeld MS, Bramsen JB, Silahtaroglu AN, Lamy P, Ramanathan R, Fristrup N, Jensen JL, Andersen CL, Zieger K, Kauppinen S, Ulhoi BP, Kjems J, Borre M, Orntoft TF (2009) Genomic profiling of microRNAs in bladder cancer: miR-129 is associated with poor outcome and promotes cell death in vitro. Cancer Res 69(11): 4851-4860

Guhaniyogi J, Brewer G (2001) Regulation of mRNA stability in mammalian cells. Gene 265(1-2): 11-23

Hanke M, Hoefig K, Merz H, Feller AC, Kausch I, Jocham D, Warnecke JM, Sczakiel G (2009) A robust methodology to study urine microRNA as tumor marker: microRNA-126 and microRNA-182 are related to urinary bladder cancer. Urol Oncol 28(6): 655-661

He L, Thomson JM, Hemann MT, Hernando-Monge E, Mu D, Goodson S, Powers S, Cordon-Cardo C, Lowe SW, Hannon GJ, Hammond SM (2005)
A microRNA polycistron as a potential human oncogene. Nature 435(7043): 828-833

Jemal A, Siegel R, Xu J, Ward E (2010) Cancer statistics. CA Cancer J Clin 60(5): 277-300

Johnstone DB, Holzman LB (2006) Clinical impact of research on the podocyte slit diaphragm. Nat Clin Pract Nephrol 2(5): 271-282

Lehmann U, Hasemeier B, Christgen M, Muller M, Romermann D, Langer F, Kreipe H (2008) Epigenetic inactivation of microRNA gene hsa-mir-91 in human breast cancer. J Pathol 214(1): 17-24

Mitchell PS, Parkin RK, Kroh EM, Fritz BR, Wyman SK, PogosovaAgadjanyan EL, Peterson A, Noteboom J, O'Briant KC, Allen A, Lin DW, Urban N, Drescher CW, Knudsen BS, Stirewalt DL, Gentleman R, Vessella RL, Nelson PS, Martin DB, Tewari M (2008) Circulating microRNAs as stable blood-based markers for cancer detection. Proc Natl Acad Sci U S A 105(30): 10513-10518

Nagel R, le Sage C, Diosdado B, van der Waal M, Oude Vrielink JA, Bolijn A, Meijer GA, Agami R (2008) Regulation of the adenomatous polyposis coli gene by the miR-135 family in colorectal cancer. Cancer Res 68(14): 5795-5802

Planz B, Jochims E, Deix T, Caspers HP, Jakse G, Boecking A (2005) The role of urinary cytology for detection of bladder cancer. Eur J Surg Oncol 31(3): 304-308

Sangar VK, Ragavan N, Matanhelia S S, Watson M W, Blades R A (2005) The economic consequences of prostate and bladder cancer in the UK. BJU Int 95(1): 59-63

Schmittgen TD, Lee EJ, Jiang J, Sarkar A, Yang L, Elton TS, Chen C (2008) Real-time PCR quantification of precursor and mature microRNA'. Methods 44(1): 31-38

Schrier BP, Hollander MP, van Rhijn BW, Kiemeney LA, Witjes JA (2004) Prognosis of muscle-invasive bladder cancer: difference between primary and progressive tumours and implications for therapy. Eur Urol 45(3): 292-296

Valadi H, Ekstrom K, Bossios A, Sjostrand M, Lee JJ, Lotvall JO (2007) Exosome-mediated transfer of mRNAs and microRNAs is a novel mechanism of genetic exchange between cells. Nat Cell Biol 9(6): 654-659

van Rhijn BW, Lurkin I, Chopin DK, Kirkels WJ, Thiery JP, van der Kwast TH, Radvanyi F, Zwarthoff EC (2003) Combined microsatellite and FGFR3 mutation analysis enables a highly sensitive detection of urothelial cell carcinoma in voided urine. Clin Cancer Res 9(1): 257-263

Voorhoeve PM, le Sage C, Schrier M, Gillis AJ, Stoop H, Nagel R, Liu YP van Duijse J, Drost J, Griekspoor A, Zlotorynski E, Yabuta N, De Vita G, Nojima H, Looijenga LH, Agami R (2006) A genetic screen implicates miRNA-372 and miRNA-373 as oncogenes in testicular germ cell tumors. Cell 124(6): 1169-1181

Zwarthoff EC (2008) Detection of tumours of the urinary tract in voided urine. Scand J Urol Nephrol Suppl 218: 147-153

This work is published under the standard license to publish agreement. After 12 months the work will become freely available and the license terms will switch to a Creative Commons Attribution-NonCommercial-Share Alike 3.0 Unported License. 